\title{
NOTES
}

\section{Emendation of Thiobacillus perometabolis London and Rittenberg 1967}

\author{
YOKO KATAYAMA-FUJIMURA AND HIROSHI KURAISHI* \\ Faculty of Agriculture, Tokyo University of Agriculture and Technology, 3-Saiwaicho, Fuchu, Tokyo 183, \\ Japan
}

An emended description of Thiobacillus perometabolis type strain THI 023 (= ATCC 23370) is presented. T. perometabolis grows in autotrophic media containing reduced inorganic sulfur compounds and in heterotrophic media containing single carbon sources, contrary to the original description.

In 1967, Thiobacillus perometabolis ATCC $23370^{\mathrm{T}}$ (type strain) was isolated by London and Rittenberg, who described this organism on the basis of one strain (i.e., the monotype) (4). The name Thiobacillus perometabolis appeared on the Approved Lists of Bacterial Names (6).

London and Rittenberg did not observe autotrophic growth of $T$. perometabolis at the expense of reduced inorganic sulfur compounds or heterotrophic growth at the expense of single carbon sources (4). However, we have observed growth of strain THI $023^{\mathrm{T}}\left(=\right.$ ATCC $\left.23370^{\mathrm{T}}\right)$ in autotrophic medium supplemented with thiosulfate, elemental sulfur, or tetrathionate and also in heterotrophic medium supplemented with alanine, glutamate, malate, citrate, succinate, or aspartate. Therefore, $T$. perometabolis was deemed to be a facultatively chemolithotrophic organism $(2,3)$. The mode for energy yielding is of great significance in the classification and identification of Thiobacillus species $(1,7)$, and the original description of $T$. perometabolis can lead to misidentifications of such bacteria.

In this paper we emend the description of $T$. perometabolis with regard to nutritional requirements and add new characters determined in a previous study $(2,3)$.

Description of Thiobacillus perometabolis London and Rittenberg 1967 emend. Katayama-Fujimura and Kuraishi. The description of this organism is based on the characteristics of type strain THI 023.

(i) Cell morphology. Rod-shaped cells (average dimensions, 0.4 to $0.5 \mu \mathrm{m}$ wide by 1.1 to $1.7 \mu \mathrm{m}$ long) with rounded ends. Cells occur singly or in pairs. Motile by means of a single polar flagellum. Nonsporeforming. Gram negative. Not acid-alcohol-fast.

(ii) Colonial appearance. Colonies on yeast extract-thiosulfate medium are circular, entire, convex, smooth, creamy white, opaque, and about 1 to $3 \mathrm{~mm}$ in diameter after 1 week of incubation. Colonies on thiosulfate-mineral salts agar are circular, entire, convex, smooth, creamy white, and opaque, developing a brown center with age; these colonies are about $0.5 \mathrm{~mm}$ in diameter after 10 days of incubation.

(iii) Biochemical and physiological properties. $T$. perometabolis is obligately aerobic, and anaerobic growth is not observed in the presence of potassium nitrate.

This organism is a facultative chemolithotroph and grows slowly in heterotrophic media containing 20 to $40 \mathrm{mM}$ substrate, such as alanine, glutamate, malate, citrate, succinate, or aspartate, after a long lag phase (about 2 weeks). The lag phase is shortened by adding thiosulfate to the media. Furthermore, this organism grows in mixotrophic media supplemented with $\alpha$-ketoglutarate, serine, or histidine. Weak growth, as determined by colony formation on plates and by optical density in liquid media, is observed with mixotrophic media containing glucose or gluconate. This organism grows in liquid inorganic salts media supplemented with thiosulfate, elemental sulfur, or tetrathionate; this growth is accompanied by a decrease in the $\mathrm{pH}$ of the media. Thiocyanate does not support growth.

Potassium nitrate, ammonium chloride, and urea are utilized as nitrogen sources. Glutamate and aspartate are utilized as both nitrogen and carbon sources.

Growth occurs at 15 to $42^{\circ} \mathrm{C}$; optimum growth occurs between 35 and $37^{\circ} \mathrm{C}$.

Growth occurs at pH 5.0 to 7.0 , and optimum growth occurs at $\mathrm{pH} 5.5$ to 6.0 in thiosulfateyeast extract medium.

Gelatin is not liquefied.

Guanine-plus-cytosine content: $65.0 \mathrm{~mol} \%$.

Ubiquinone system: ubiquinone 8 . 
This organism has hexadecanoic acid, hexadecenoic acid plus cyclopropane acid of $\mathrm{C}_{17}$, and octadecenoic acid plus cyclopropane acid of $\mathrm{C}_{19}$ as its major non-hydroxylated cellular fatty acids and 3-hydroxydecanoic acid and 3-hydroxydodecanoic acid as its hydroxylated fatty acids.

Isolated from soil (4).

The type strain of $T$. perometabolis is THI 023. This strain has been deposited with the American Type Culture Collection under accession number ATCC 23370 and with the Institute of Applied Microbiology, University of Tokyo, Tokyo, Japan, under accession number IAM 12132.

Another strain, strain THI 024 (= ATCC 27793), which was originally isolated by Myers and Millar (5), is regarded as a separate species, Thiobacillus rapidicrescens (2).

We thank K. Komagata, Institute of Applied Microbiology, University of Tokyo, Tokyo, Japan, for useful discussions.

\section{LITERATURE CITED}

1. Hutchinson, M., K. I. Johnstone, and D. White. 1969. Taxonomy of the genus Thiobacillus: the outcome of numerical taxonomy applied to the group as a whole. J. Gen. Microbiol. 57:397-410.

2. Katayama-Fujimura, Y., I. Kawashima, N. Tsuzaki, and H. Kuraishi. 1983. Reidentification of Thiobacillus perometabolis ATCC 27793 and Thiobacillus sp. strain A2 with reference to a new species, Thiobacillus rapidicrescens $\mathrm{sp}$. nov. Int. J. Syst. Bacteriol. 33:532-538.

3. Katayama-Fujimura, Y., N. Tsuzaki, and H. Kuraishi. 1982. Ubiquinone, fatty acid and DNA base composition determination as a guide to the taxonomy of the genus Thiobacillus. J. Gen. Microbiol. 128:1599-1611.

4. London, J., and S. C. Rittenberg. 1967. Thiobacillus perometabolis nov. sp., a non-autotrophic thiobacillus. Arch. Mikrobiol. 59:218-225.

5. Myers, P. S., and W. N. Millar. 1975. Nonautotrophic Thiobacillus in acid mine water. Appl. Microbiol. 30:884 886.

6. Skerman, V. B. D., V. McGowan, and P. H. A. Sneath (ed.). 1980. Approved lists of bacterial names. Int. J. Syst. Bacteriol. 30:225-420.

7. Vishniac, W. V. 1974. Genus Thiobacillus, p. 456-461. In R. E. Buchanan and N. E. Gibbons (ed.), Bergey's manual of determinative bacteriology, 8th ed. The Williams \& Wilkins Co., Baltimore. 